\title{
Cytogenetic and molecular characterization in gonadal tissue of patients with ovotesticular syndrome and gonadal dysgenesis $46, X Y$ and $46, X X$
}

\section{Caracterización citogenética y molecular en tejido gonadal de pacientes con síndrome ovotesticular y disgenesia gonadal $46, X Y$ y $46, X X$}

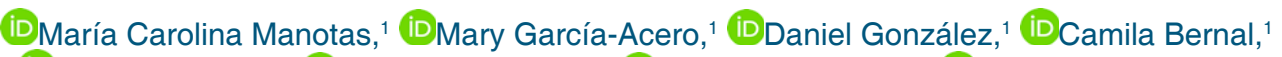
DMariana Guerra, ${ }^{1}$ DOIga Moreno-Niño, ${ }^{1}$ DFernando Suárez, ${ }^{1,2}$ (DCamila Céspedes, ${ }^{1,2}$
\end{abstract} (DCatalina Forero, ${ }^{1,2}$ (DJaime Pérez, ${ }^{1,2}$ (D)Adriana Rojas. ${ }^{1}$

Key Words: gonadal dysgenesis,

ovotesticular syndrome, FISH, MLPA, aCGH, SRY

\section{Corresponding author:}

* Adriana Rojas, Dirección Instituto de Genética Humana, Facultad de Medicina, Pontificia Universidad

Javeriana. 32 building, Cra. 7 No.40-

62.110231.

Bogotá- Colombia. Email: rojas-adriana@ javeriana.edu.co

\section{Abstract}

Objectives: The etiology of gonadal dysgenesis and the ovotesticular syndrome is unknown in most cases. The aim of the study was to perform cytogenetic and molecular characterization of a group of patients with ovotesticular syndrome and complete gonadal dysgenesis from peripheral blood and gonadal tissue samples.

Materials and methods: A total of 6 patients were included, 3 with 46,XX ovotesticular syndrome diagnosis, 1 diagnosed with 46 , XY ovotesticular syndrome; 1 suspected with $46, \mathrm{XX}$ gonadal dysgenesis, and 1 with $46, \mathrm{XY}$ complete gonadal dysgenesis.

Results: All patients were evaluated with karyotype, fluorescence in situ hybridization (FISH) for SRY, multiplex ligation-dependent probe amplification (MLPA) and comparative genomic hybridization (aCGH) in peripheral blood samples. In cases with available gonadal tissue, the levels of genetic expression of SOX3, SRY, and SOX9 were determined by real-time PCR and immunofluorescence.

Rearrangements involving SRY gene were ruled out. No deletions/duplications or copy-number variations (CNVs) were identified as the etiology for the sexual development disorder in any of the studied patients. In one case of $46, \mathrm{XX}$ ovotesticular syndrome, the gonadal karyotype was different from the karyotype in peripheral blood. Aberrant expression of SOX3 and SOX9 in gonadal tissue was observed in one case of 46,XX ovotesticular syndrome.

Conclusions: Lower levels of SRY and SOX9 expression were documented in the gonadal tissue of a case of $46, \mathrm{XY}$ ovotesticular syndrome, in commparison with the levels in human cellular lines of embryonic testicle and Sertoli cells. Cytogenetic and molecular studies of gonads complementary to peripheral blood studies have the potential of enhancing the understanding of sexual development disorders in patients who are $\mathrm{XX}$ or $\mathrm{XY}$ in peripheral blood.

Citation: Manotas M. C., García-Acero M., González D., Bernal C., Guerra M., Moreno-Niño O., et al. Cytogenetic and molecular characterization in gonadal tissue of patients with ovotesticular syndrome and gonadal dysgenesis 46,XY and 46,XX. Rev Mex Urol. 2021;81(4):pp. 1-19

${ }^{1}$ Pontificia Universidad Javeriana, Bogotá, Colombia.

${ }^{2}$ Hospital Universitario San Ignacio, Pontificia Universidad Javeriana, Bogotá, Colombia.

Received: May 15, 2021

Accepted: August 05, 2021

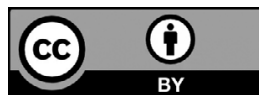




\section{Cytogenetic and molecular characterization in gonadal tissue of patients with ovotesticular... Manotas M, C., et al.}

Resumen

Objetivos: La etiología de la disgenesia gonadal y el síndrome ovotesticular se desconoce en la mayoría de los casos. Para realizar la caracterización citogenética y molecular de un grupo de pacientes con síndrome ovotesticular y disgenesia gonadal completa a partir de muestras de sangre periférica y tejido gonadal.

Material y métodos: Se incluyeron un total de 6 pacientes, 3 con diagnóstico de síndrome ovotesticular 46, XX, uno diagnosticado con 46, $\mathrm{XY}$ síndrome ovotesticular; uno con sospecha de disgenesia gonadal 46, XX y otro con disgenesia gonadal completa 46, XY.

Resultados: Todos los pacientes fueron evaluados con cariotipo, hibridación in situ fluorescente (FISH) para SRY, amplificación de sonda dependiente de ligación múltiple (MLPA) e hibridación genómica comparativa (aCGH) en muestras de sangre periférica. En los casos con tejido gonadal disponible, los niveles de expresión genética de SOX3, SRY y SOX9 se determinaron mediante PCR en tiempo real e inmunofluorescencia. Se descartaron reordenamientos relacionados con el gen SRY. No se detectaron deleciones/duplicaciones o variaciones en el número de copias (NVC) como etiología del trastorno del desarrollo sexual en ninguno de los pacientes estudiados. En un caso de síndrome ovotesticular 46, XX, el cariotipo gonadal era diferente del cariotipo en sangre periférica. Se observó expresión aberrante de SOX3 y SOX9 en tejido gonadal de un caso con síndrome ovotesticular 46, XX.

Conclusiones: Se documentaron niveles más bajos de expresión de SRY y SOX9 en comparación con los niveles en líneas celulares humanas de testículo embrionario y Sertoli en el tejido gonadal de un caso con síndrome ovotesticular 46, XY. Los estudios citogenéticos y moleculares de las gónadas como complemento del estudio de sangre periférica tienen el potencial de enriquecer la comprensión de los trastornos del desarrollo sexual en pacientes que son $\mathrm{XX}$ o XY en sangre periférica.

\section{Introduction}

Sexual development in mammals is genetically determined. It is defined at a phenotypical level by the development of gender-specific anatomy, physiology, and behavior. At a cellular level, sex is defined by the chromosomal complement and the genetic orchestration. ${ }^{(1,2)}$ Sex-specific gonadal development starts with the formation of the bipotential gonad, which differentiates to testicular or ovarian tissue. The differentiation process depends on the activation of testis-specific or ovary-specific pathways, with parallel repression of the opposite pathway. ${ }^{(3,4)}$ 
Cytogenetic and molecular characterization in gonadal tissue of patients with ovotesticular... Manotas M, C., et al.

The process for testis differentiation requires the participation of genes that belong to the SOX family. The SRY, located in the chromosome Y, was the first gene of the SOX family to be identified. This gene encodes a transcription factor which is sufficient and necessary to induce testis development. ${ }^{(5)}$ After its translation, the SRY protein translocates to the nucleus and interacts with the steroidogenic factor 1 (SF-1). The SRY protein and SF-1 bind to equal or similar places located within a testis-enhancer region in $S O X 9$, inducing SOX9 expression. ${ }^{(4-7)}$ It has been determined that SF-1 (NR5A1 gene) regulates different developmental and functional aspects of the suprarenal gland and reproductive system. The activation of the expression of the $A H M$ gene that encodes the Anti-Müllerian factor or hormone $(A M H)$ is prominent among those aspects. ${ }^{(8)}$ The activation of the $A M H$ is also regulated by the binding of the WT1 transcription factor to the Anti-Müllerian hormone receptor 2 (AMHR2) promoter. ${ }^{(9)}$ The WT1 has been described as a transcription factor necessary for early gonad development. The WT1 and LHX9 function together as direct activators of SF-1. ${ }^{(10)}$ Another gene involved in sexual development is NROB1(DAX1 protein). This gene, located in chromosome X (p21.3), encodes an orphan nuclear receptor that functions as a transcriptional repressor for many other genes, including NR5A1 and some genes that encode steroidogenic enzymes. ${ }^{(11,12)}$

In ovarian differentiation, the participation of WNT4, RSPO1, and B-catenin (CTNNB1) is known. ${ }^{(3,4)}$ In XX gonads, the WNT4 and RSPO1 signaling factors favor and stabilize the expression of the transcription factor CTNNB1 (known as B-catenin), which participates in SOX9 genetic repression. The WNT4 is widely known as a necessary factor for early ovarian development. ${ }^{(13)}$

Alterations in the testis-specific or ovarian-specific signaling pathways during gonadal development result in 'disorders of sex development' (DSD). ${ }^{(3)}$ DSD are defined as congenital conditions with atypical gonadal or anatomic development of chromosomic sex. ${ }^{(14)}$

Collectively, DSD occur in fewer than 1 in 4,500-5,000 live births. DSD include a clinical spectrum ranging from hypospadias ( 1 in 200300 births) to more severe conditions (exact prevalence unknown). Such is the case of the $46, \mathrm{XY}$ or $46, \mathrm{XX}$ ovotesticular syndrome and $46, \mathrm{XY}$ or $46, \mathrm{XX}$ gonadal dysgenesis. ${ }^{(4)}$ The presence of internal and external female genitalia despite a 46,XY karyotype is the main characteristic of 46,XY complete gonadal dysgenesis, a DSD formerly known as XY sex reversal. ${ }^{(15)}$ Conversely, 46,XX gonadal dysgenesis is a primary ovarian failure that leads to premature ovarian insufficiency in otherwise normal 46,XX. ${ }^{(16)}$ The presence, histologically confirmed, of testicular and ovarian tissue in a case of $46, \mathrm{XX}$ or $46, \mathrm{XY}$ karyotype, defines the ovotesticular syndrome. The ovotesticular syndrome was previously known as true hermaphroditism. ${ }^{(17)}$ There is a hypothesis of an alteration in the signaling pathways involved in gonadal development as the cause for DSD, ${ }^{(3)}$ but the etiology of gonadal dysgenesis and ovotesticular syndrome in most cases is unknown. ${ }^{(18)}$

Regarding XY gonadal dysgenesis, two types have been described: Complete (or pure), and partial. Partial gonadal dysgenesis is characterized by the presence of ambiguous genitalia, with or without Müllerian structures. Genes involved in partial gonadal dysgenesis include: $S R Y$ (by genic deletion or loss-of-function mutation); ${ }^{(19,20)}$ NR5A1 (by loss-of-function 
mutations); $\mathrm{DHH}$ (by loss-of-function mutation, homocygous or heterocygous, affecting Leydig's cell differentiation); and MAP3K1 (heterocygous gain-of-function mutations, associated with increased $\beta$-catenine expression and SOX9 suppression). ${ }^{(21-23)}$ Also, in patients with 46,XY gonadal dysgenesis, partial Xp duplications, including NROB1 gene and $9 \mathrm{p}$ chromosomal deletions, including DMRT1 and DMRT2 genes, have been described. ${ }^{(21-24)}$ Molecular mechanisms involving DMRT1 and $D M R T 2$ leading to gonadal dysgenesis are not completely understood. ${ }^{(24)}$

Testicular syndrome, or 46,XX sex reversal, is caused by translocations involving SRY gene in $80 \%$ of the cases. ${ }^{(25)}$ Regarding SRY-negative cases, copy number variations (CNVs) affecting SOX3, SOX9, and NR5A1 genes, have been described. ${ }^{(25-28)}$ The $S O X 3$ encodes a protein similar to SRY, sharing $90 \%$ of aminoacid identity in their DNA-binding HMG domain. ${ }^{(29)}$ Like SRY, this protein works synergistically with SF1 in the activation of the SOX9-enhancing region. ${ }^{(30)}$

For the 46,XX ovotesticular syndrome, a small proportion of individuals with this condition have a fragment of the $\mathrm{Y}$ chromosome that includes the SRY gene, translocated to one of the X chromosomes. Likewise, CNVs involving SOX9, SOX3, and NROB1; ${ }^{(18)}$ and a recurrent variant (p.Arg92Gln) in heterozygous status in NR5A1 have been described. ${ }^{(31)}$ However, $46, \mathrm{XY}$ ovotesticular syndrome is extremely rare and represents approximately $10-12.5 \%$ of ovotesticular syndrome cases. Pathogenic variants involving $S R Y$, SOX9, DMRT1, and NROB1 genes have been described as the cause. ${ }^{(32)}$
The objective of this paper was two-fold. First, to characterize the cytogenetic and molecular characterization of a group of patients with ovotesticular syndrome and complete gonadal dysgenesis from peripheral blood and gonadal tissue samples. Second, to analyze the role of pro-testis- and pro-ovarian-pathway genes in the clinical phenotype.

\section{Materials and Methods \\ Subjects of Research}

This study was approved by the Ethics Committee of the Hospital Universitario San Ignacio, Bogotá D.C., Colombia (FM-CIE-0445-17). The informed consent was obtained from the subjects of research: 4 patients with 46,XX SRY(-) DSD ( 3 cases with ovotesticular syndrome diagnosis and 1 case of suspected gonadal dysgenesis), and 2 patients with 46,XY SRY(+) DSD ( 1 case with ovotesticular syndrome and 1 case with gonadal dysgenesis) (Fig. 1). All individuals were evaluated by the transdisciplinary joint committee of the Hospital San Ignacio, Bogotá D.C., Colombia. Genetic tests included karyotype, FISH for SRY, and MLPA from blood samples. ${ }^{(33)}$ In some ca--ses, the tests were also performed in gonadal tissue. In this study, all selected patients were analyzed for CNVs in DNA samples from peripheral blood. In cases where a biopsy was performed as part of the diagnostic approach, molecular tests were also performed from cultures of gonadal tissue fragments (Fig. 1). 
Figure 1. Summary of the studied cases with DSD and applied tests. Created with BioRender.com FIGURE 1.

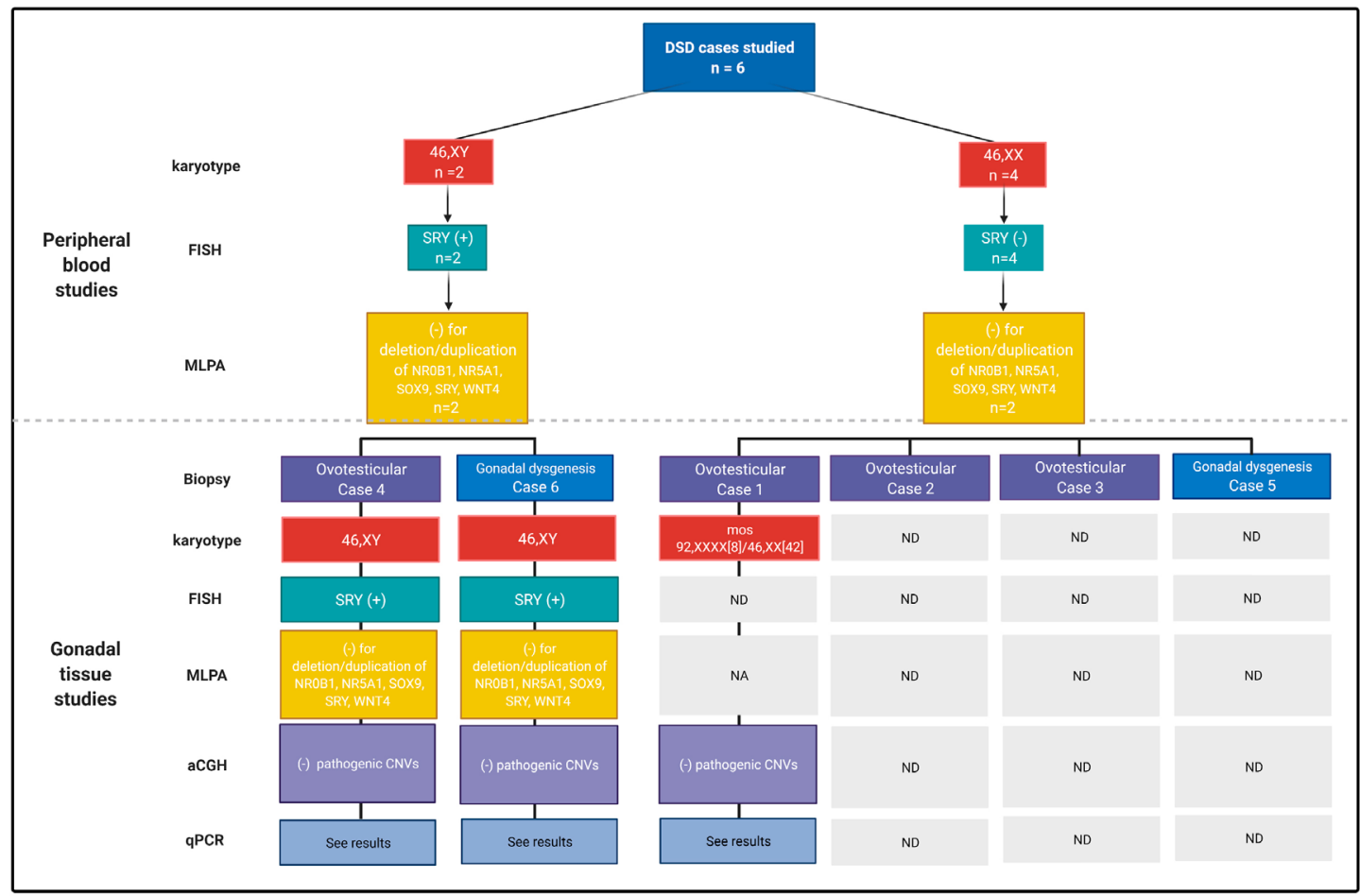

Biological samples

Peripheral blood samples were used for karyotype, FISH, MLPA, and CGH. In some cases, gonad biopsies were obtained (cases 1, 4, and 6). Gene-expression experiments used samples of Sertoli cell cultures, isolated from human adult testicle (ScienCell\#4520) as control tissue. In addition, cell line HS 1. Tes (ATCC CRL7002 ${ }^{\mathrm{TM}}$ ) was used. This cell line is composed of human testis cells of second-trimester embryo.

\section{Cytogenetic Analysis (Karyotype and FISH)}

A cytogenetic analysis was performed from a lymphocyte culture obtained in peripheral blood and stimulated with phytohaemaggluti- nin (Gibco 10576015), following the protocol described by the research group. ${ }^{(34)}$

The gonad karyotype was obtained from gonadal tissue biopsy cultures. The tissue was mechanically digested and cultured with RPMI medium and $20 \%$ SFB. Chromosomes prepared in slides were treated with $\mathrm{HCl}$ and Wright stain for G-banding. A total of 50 cells in metaphase were analyzed with a 550-band resolution. Molecular cytogenetic analysis through fluorescence in situ hybridization (FISH) was performed with the use of an SRY-specific gene probe (SRY probe, Cytocell Aquarius). This reagent contains probes labelled in blue for the $\mathrm{X}$ chromosome centromere (DXZ1), a specific probe for SRY gene labelled in red (Yp11.31), and probes labelled in green fluorescence for Yq12 (DYZ1). 


\section{Cytogenetic and molecular characterization in gonadal tissue of patients with ovotesticular... Manotas M, C., et al.}

\section{Extraction of genomic DNA}

The extraction of DNA from peripheral blood and the gonad biopsy was performed using the Quick-DNA ${ }^{\mathrm{TM}}$ Universal kit, following the manufacturer's instructions. The concentration and purity of the DNA were evaluated by spectrometry with the NanoDrop ${ }^{\mathrm{TM}}$. The quality of the DNA was assessed through electrophoresis in $1 \%$ agarose gel.

Multiplex ligation-dependent probe amplification (MLPA)

Possible deletions and duplications of SOX9, NROB1, NR5A1, SRY, and WNT4 genes were studied with the MLPA SALSA P185-B2 Intersex kit (08 version; May 7, 2015) (MRC Holland), following the manufacturer's instructions. After 35 PCR-amplification cycles, the amplification products were separated with the genetic analyzer ABI 3100. The data was analyzed using the Coffalyser (MRC Holland $®$ ). Each sample underwent duplicate analysis. Peak areas for each probe were normalized to the average of peak areas in the three controls. Samples of DNA that showed a reduction or an increase in the values of the MLPA peak area were analyzed again using the same procedure.

Matrix-comparative genomic hybridization $(\mathrm{CGH})$

The analysis of CNVs was performed with CGH using peripheral blood DNA and gonadal tissue culture, with a minimum DNA concentration of $66,592 \mathrm{ng} / \mathrm{ul}$. The extracted DNA was sent to Macrogen Inc. for processing of the array chromosomal study with the Comparative Genomic Hybridization (Array-CGH) technique on an Illumina Infinium OmniExpress-24 platform. A bioinformatics analysis was performed with the GenomeStudio v2011.1 Genotyping 1.9.4, cnvPartition_v3.2.0. software. Genomic coordinates have been obtained from the reference human sequence NCBI37/hg19 (UCSC Genome Browser 2009).

\section{Real time PCR ( $q P C R)$}

Messenger RNA levels for SRY, SOX9, and SOX3 genes were determined by q-PCR in gonadal tissue, Hs 1.Tes, and Sertoli cells. For all qPCR assays, RNA was isolated from tissue and/or cellular cultures with $100 \%$ confluence using the agent Trizol (Invitrogen ${ }^{\circledR}$ ), following the manufacturer's specifications. After RNA collection and quantification, the corresponding cDNA was synthetized. Once cDNA was procured, qPCR amplifications were performed using specific primers for SOX3, SOX9, and $S R Y$ (Table SI). For each $10 \mu$ of q-PCR-TR reaction, $2.5 \mu$ of DNA from the sample were added to a mixture containing $5 \mu$ of SYBR Green (Invitrogen ${ }^{\circledR}$ ), $0.5 \mu$ of each primer in a $10 \mu \mathrm{M}$ / concentration, and $1.5 \mu$ of ultrapure nuclease-free water. The results were analyzed using the Ct comparative method or $2-\Delta \Delta \mathrm{Ct}$ as a strategy for relative quantification, with $G A P D H$ as the reference gene. Gene expression results were graphically represented and analyzed with the software GraphPad Prim, version 6. 


\section{Cytogenetic and molecular characterization in gonadal tissue of patients with ovotesticular... Manotas M, C., et al.}

Immunofluorescence

Protein expression of SOX3, SOX9, and SRY was evaluated through indirect immunofluorescence in cultured cells from right and left gonads of a case with ovotesticular 46,XX SRY (-) DSD and in Sertoli cells as the positive control. On each slide, 100,000 cells from gonadal culture were seeded for immunofluorescence. Cells were fixed, washed, permeabilized, and incubated with primary antibodies directed against SRY (Anti-SRY antibody [OT13C8] ab140309) 1:100; SOX9 (Anti-SOX9 ab3697) 1:100; and SOX3 (Anti-H-SOX3 AF2569 R\&D systems). The secondary antibodies were Alexa Fluor 594 Donkey Anti-Goat IgG (orange fluorochrome), Alexa Fluor 488 Invitrogen Goat Anti-Mouse IgG (green fluorochrome), and Alexa Fluor 647 Invitrogen Goat Anti-Rabbit IgG (red fluorochrome). Finally, slide mounting was performed with $7 \mathrm{ul}$ of mounting medium ProLongTM Gold Antifade Mountant with DAPI (Invitrogen, P36931) for staining of contrast nuclei. Images with a $640 \times 640$ pixels resolution were obtained with a laser scan confocal microscope FV1000 (Olympus, Tokyo, Japan) using the oil immersion objective with UPLSAPO 60 x 1.35 NA. Images were processed using the software ImageJ.

\section{Results}

Six patients with DSD were included: 3 with 46, XX SRY(-) ovotesticular syndrome diagnosis, 1 patient with 46,XY SRY(+) ovotesticular syndrome diagnosis, 1 patient suspected with 46,XX SRY(-) gonadal dysgenesis, and 1 patient with complete 46,XY SRY(+) gonadal dysgenesis (Table I). 


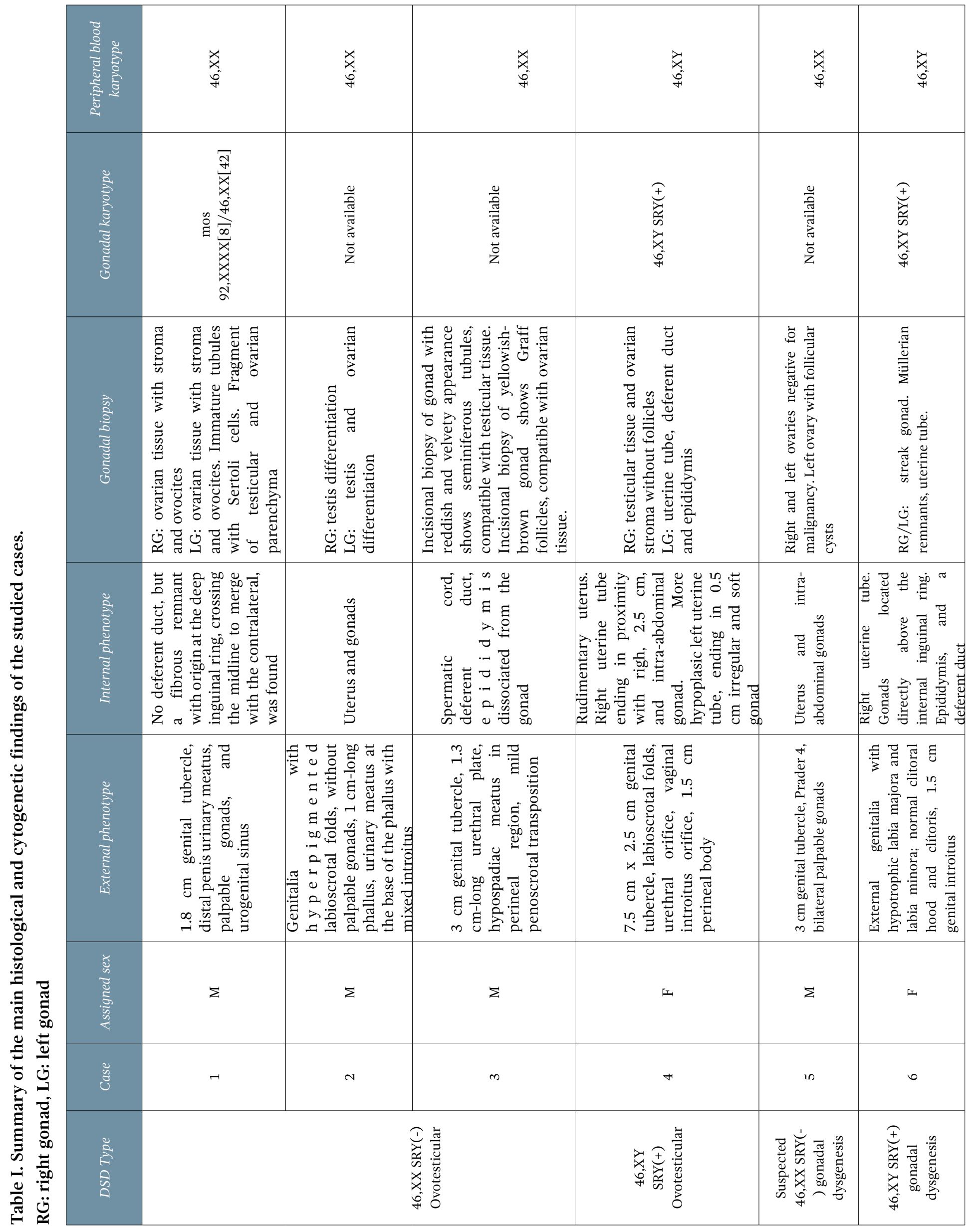


Cases with ovotesticular syndrome 46,XX SRY(-) diagnosis

Case 1

Case 1 was an individual with ambiguous genitalia, assigned male. Physical examination during neonatal period showed a $1.8 \mathrm{~cm}$ genital tubercle, distal penis urinary meatus, palpable gonads, and urogenital sinus. The patient had peripheral blood karyotype 46,XX; negative FISH for SRY (Fig. 2 A and B), negative MLPA Intersex, and negative aCGH for CNVs associated with ovotesticular syndrome. Karyotype in gonadal tissue showed a mosaicism characterized by 2 cell lines 92,XXXX[8]/46,XX[42]. ${ }^{(33)}$ The results of conventional cytogenetic, FISH and MLPA assays were included in a previous work of our research group. ${ }^{(33)}$

Figure 2. Cytogenetic analysis case 1. A. Karyotype by G-banding in peripheral blood, 46,XX. B. SRY FISH in peripheral blood

A

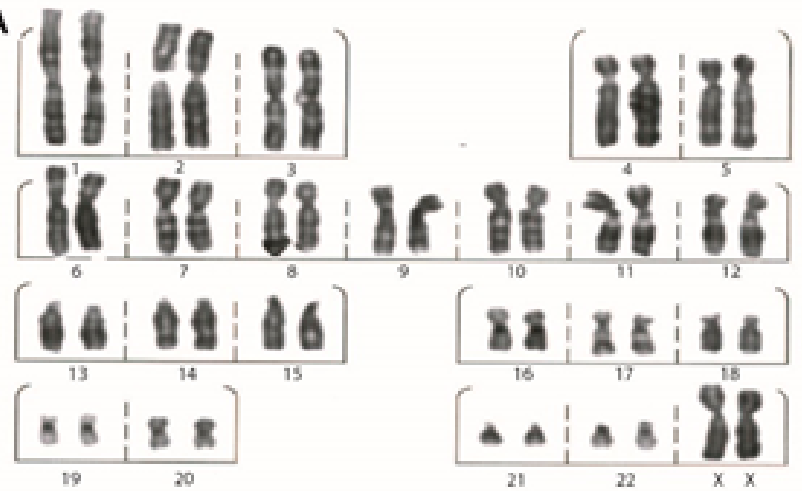

B

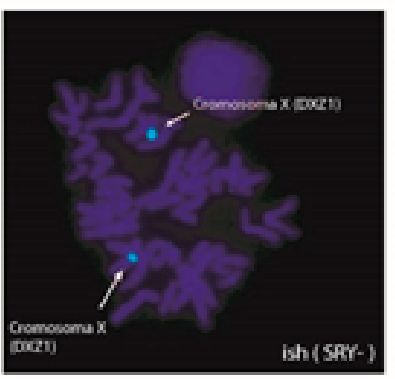

FIGURE 2

The image shows the metaphase of a 46,XX SRY (-) cell obtained with a Cytocell detection kit that uses three fluorescent probes. X chromosome centromere region (DXZ1) labelled blue, $S R Y$ gene (Yp11.31) labelled red, and Yq12 (DYZ1) labelled with green fluorescence. The results of conventional cytogenetic, FISH and MLPA assays were included in a previous work of our research group.

Levels of mRNA for $S R Y$, SOX9, and $S O X 3$ in gonadal tissue were determined by qPCR. Results from right and left gonads showed that expression levels of $S R Y$ and SOX9 mRNA were lower than the levels detected in Sertoli cells and embryonic human testis cells. Regarding SOX3, an increased expression was found in the left gonad (Fig. 3 A). Such expression levels of SRY and SOX9 in both gonads were consistent with low protein levels detected in immunofluorescence assays (Fig. 3 B). Regarding SOX3, protein expression was found only in the left gonad, which correlates with findings for mRNA (Fig. 3 B). 
Figure 3. Gene expression of $S O X 3, S O X 9$, and $S R Y$
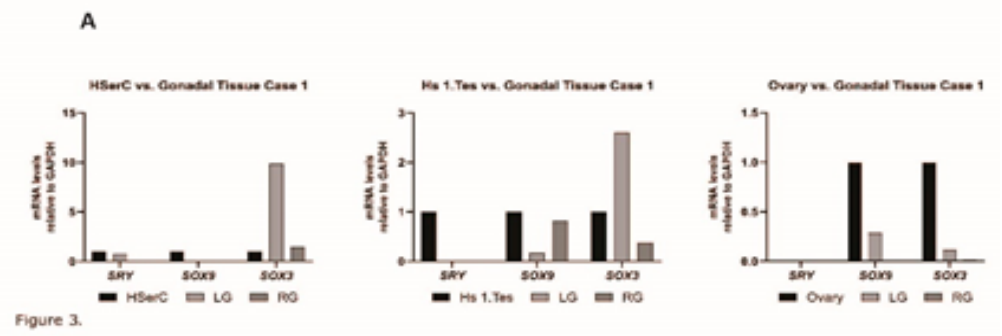

B

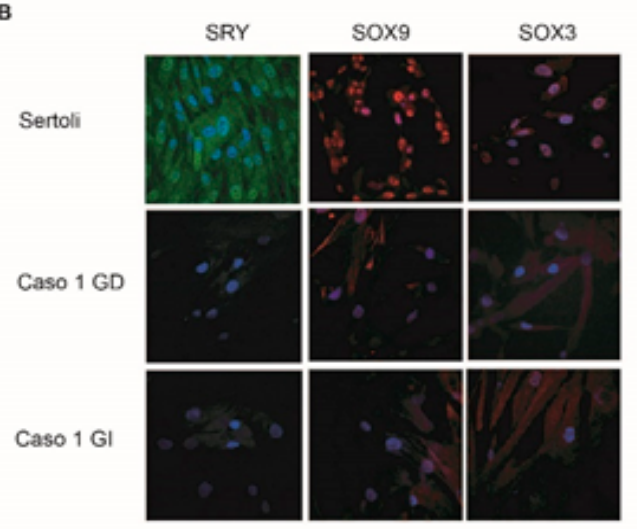

Figura 3

A. Gene expression of SOX3, SOX9 and SRY mRNA relative to GAPDH in right and left gonads of the case with 46,XX SRY(-) ovotesticular syndrome (case 1). B. Inmunofluoresence for SOX3, SOX9 and SRY in right and left gonads in case 1 and Sertoli cell as control. Alexa fluor 594 Donkey Anti-Goat IgG used as secondary antibody for SOX3 (orange fluorochrome), Alexa fluor 488 Invitrogen Goat Anti-Mouse IgG for SRY (green fluorochrome), Alexa fluor 647 Invitrogen Goat Anti-rabbit IGG for SOX9 (red fluorochrome). Nuclei are observed stained in blue.

\section{Case 2}

Case 2 was an individual with ambiguous genitalia, assigned male. The patient had karyotype with 46,XX chromosomic complement, SRY-negative FISH, and negative MLPA. No CNVs were detected with aCGH from peripheral blood DNA. There are no gonadal cytogenetic and/or molecular results for this patient, as no gonadal tissue was available for the study.

\section{Case 3}

Case 3 was an individual assigned male, with evidence of hypospadias and bilateral cryptorchidism. Laparoscopy showed gonads of mixed aspect. One gonad had a reddish and velvety appearance, and 
the incisional biopsy showed seminiferous tubules, compatible with testicular tissue. The other gonad was yellowish-brown and the incisional biopsy showed Graff follicles, compatible with ovarian tissue. The patient had peripheral blood 46,XX karyotype, SRY-negative FISH, and negative MLPA Intersex. No pathogenic CNVs were detected with aCGH from peripheral blood DNA. There are no gonadal cytogenetic and/or molecular results for this patient, as no gonadal tissue was available for the study.

\section{Case diagnosed with 46,XY SRY(+) ovotesticular syndrome}

Case 4

Case 4 was an individual assigned female who underwent laparoscopy at age 12 due to primary amenorrhea. Histological examination of the left gonad biopsy showed uterine tube fragment, deferent duct fragment, and epididymal fragments. Histological examination in the right gonad showed evidence of testis with atrophic changes and an area suggestive of ovarian stroma. A new gonadal biopsy performed 3 years later showed gonadoblastoma in the right gonad. The patient had peripheral blood 46,XY. ish Yp11.31(SRY+) karyotype, negative MLPA Intersex, and negative aCGH for pathogenic CNVs. Gonadal karyotype, FISH, and MLPA results were consistent with those in peripheral blood. The aCGH from gonadal tissue did not detect CNVs associated with ovotesticular syndrome. Examination of genomic DNA from the right gonad showed a heterozygous loss of the $\operatorname{arr}[\mathrm{hg} 37]: 2 \mathrm{q} 14.2(121746975-121747688)$ $\mathrm{x} 1$ region involving the GLI2 gene.

For mRNA expression levels of SRY, SOX9, and SOX3, SRY levels were similar to levels in Sertoli cells and lower than levels in the Hs1. Tes in the right gonad. Relative SOX9 mRNA levels showed a differential expression in each gonad: The left gonad exhibited lower expression levels, while the right gonad showed nearly a five-fold increase compared to the control. The SOX3 mRNA expression showed an increase only in the left gonad (Fig. 4).

Figure 4. Gene expression of $S O X 3$, $S O X 9$, and $S R Y$ relative to GAPDH expression in right and left gonads in the 46,XY SRY(+) ovotesticular syndrome case (case 4).

HSerC vs. Gonadal Tissue Case 4

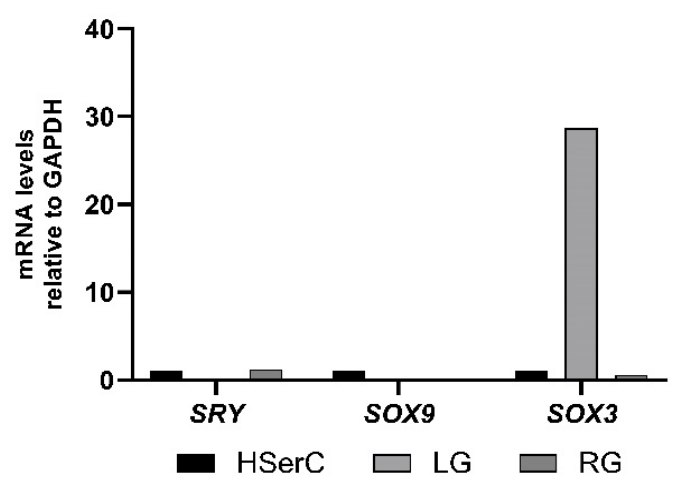

Hs 1.Tes vs. Gonadal Tissue Case 4

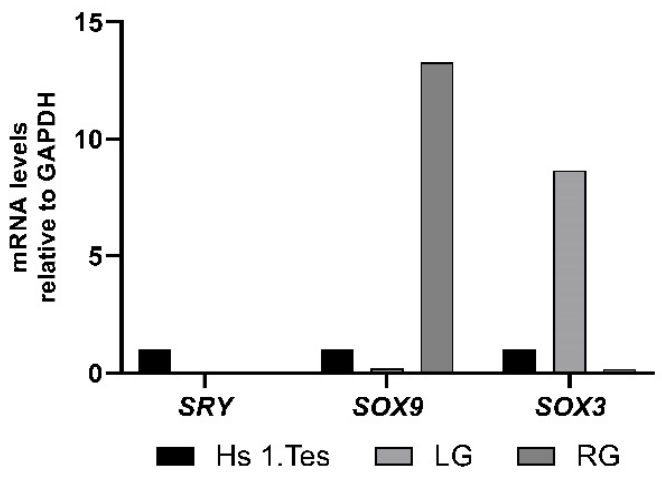

Figure 4. 


\section{Cytogenetic and molecular characterization in gonadal tissue of patients with ovotesticular... Manotas M, C., et al.}

Case suspected with 46,XX SRY(-) gonadal

dysgenesis

Case 5

Case 5 was an individual assigned male. Biopsy of right and left gonads showed ovarian tissue, with follicular cysts in the left one. The patient had peripheral blood 46,XX karyotype, $S R Y$-negative FISH, negative MLPA Intersex, negative $S R Y$ sequencing, and negative CNVs by aCGH from peripheral blood DNA. There are no gonadal cytogenetic and/or molecular results in this patient, as no gonadal tissue was available for the study.

\section{Case with 46,XY SRY(+) gonadal dysgenesis Case 6}

Case 6 was an individual assigned female, in study for amenorrhea at age 12, without evidence of uterus in imaging studies. Diagnostic laparoscopy showed two gonads located directly above the internal inguinal ring, epididymis, and a deferent duct. No Müllerian remnants were found. Gonadal biopsy reported streak gonad, Müllerian remnants, and right uterine tube. The patient had peripheral blood 46,XY. ish Yp11.31(SRY+) karyotype, negative MLPA for NROB1, NR5A1, SOX9, SRY, WNT4 deletion/duplication, and aCGH negative for CNVs associated with gonadal dysgenesis. Results of karyotype, FISH, MLPA, and aCGH in gonadal tissue were consistent with those in peripheral blood.

For SRY, SOX9 and SOX3 mRNA levels, the right gonad had $S R Y$ levels similar to those in Sertoli cells and lower than the ones in Hs1. Tes. Relative SOX9 mRNA levels were lower than levels in Sertoli cell and higher than levels in Hs1.Tes. The SOX3 expression was higher compared to Sertoli cells and Hs1.Tes.

In the left gonad, $S R Y$ levels were similar to those in Sertoli cells and lower than the ones in Hs1.Tes, while SOX9 levels were lower compared to Sertoli cells and Hs1.Tes. For SOX3, higher relative expression levels were observed compared to Sertoli cells, and similar levels to those observed in Hs1.Tes (Fig. 5).

Figure 5. Gene expression of SOX3, SOX9, and SRY relative to GAPDH in right and left gonads from the 46,XY SRY (+) gonadal dysgenesis case (Case 6 ).

HSerC vs. Gonadal Tissue Case 6

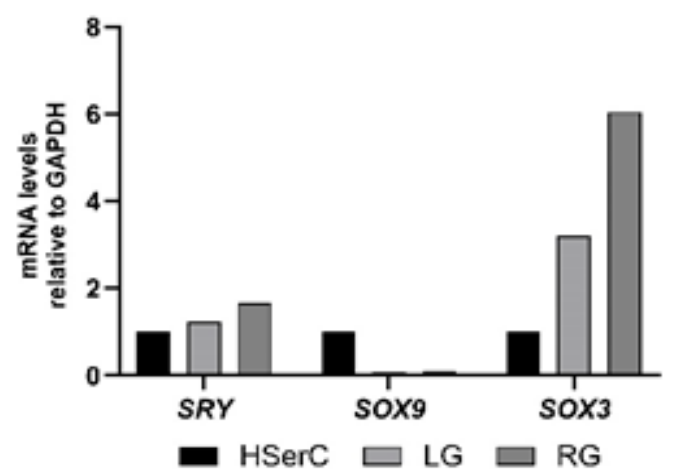

Hs 1.Tes vs. Gonadal Tissue Case 6

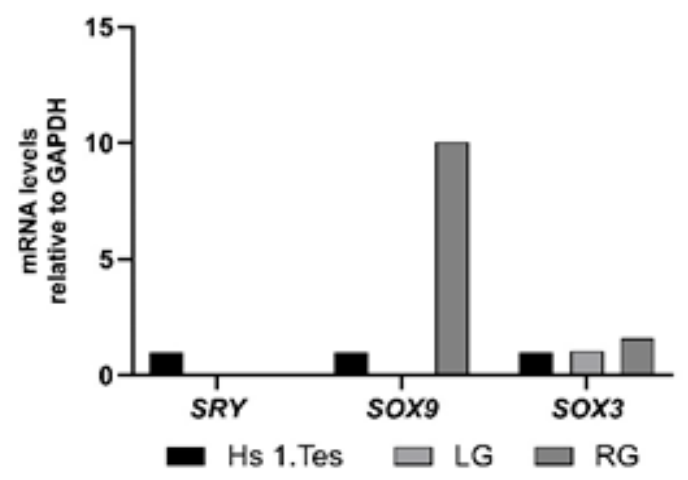

Figure 5. 


\section{Discussion}

This paper presents 3 patients with 46,XX ovotesticular syndrome, 1 with $46, \mathrm{XY}$ ovotesticular syndrome, 1 suspected with 46,XX gonadal dysgenesis, and 1 with 46,XY complete gonadal dysgenesis. Chromosomal rearrangements involving $S R Y$ gene were ruled out in the three patients during the initial diagnostic approach. Unexplainable cases of ovotesticular syndrome or gonadal dysgenesis can emerge from pathogenic variants in the pro-ovarian or pro-testis pathways. CNVs are detected in approximately $21.5 \%$ of DSD cases. ${ }^{(35)}$ For this reason, after ruling out deletions or duplications in the main genes (NR5A1, NR0B1, SOX9, SRY, and WNT4) of such pathways, a possible CNV involved in the patient's phenotype was assessed through aCGH. No CNVs were detected, however, that could explain the DSD of at least one of the cases presented, which falls into the expectations due to the test diagnostic performance.

In cases with access to gonadal tissue, cytogenetic and molecular characteristics were analyzed through karyotype, aCGH, and genic expression levels for SRY, SOX9, and SOX3 ${ }^{(3,36)}$ The study of $S O X 3$ was considered, given the synergistic function of SOX3 with SF1 in the activation of the $S O X 9$ enhancer region and due to evidence of its etiological role for XX male (sex reversal) with genomic rearrangements involving the SOX3 regulatory region. ${ }^{(26,27,30)}$

In case 1 , with $46, \mathrm{XX}$ ovotesticular syndrome, SOX 3 expression levels in gonads were higher than levels in Sertoli and Hs1.Tes. Such findings might relate to the mosaicism found in gonadic tissue, mos 92, $\mathrm{XXXX}[8] / 46, \mathrm{XX}[42]$, given that tetraploidy is associated with chromosomal unbalance in gene expression. ${ }^{(37)}$ This unbalance would explain the observed levels of SOX3 expression. The difference between karyotype in peripheral blood and karyotype in gonadal tissue is remarkable, however, given that chromosomal mosaicisms or chimerism in gonads have been previously observed, even with the presence of cells containing $\mathrm{Y}$ chromosome only in gonads. ${ }^{(38)}$ The abovementioned is supported by the hypothesis that in DSD which are unexplainable by studies in peripheral blood, gonadal mosaicism might explain the clinical phenotype of some patients, which justifies studies in gonadal biopsy.

In case 4 with $46, \mathrm{XY}$ ovotesticular syndrome, gonadal SOX3 expression levels were higher, compared to normal human Sertoli cells and Hs1.Tes. Also, gonadal SRY and SOX9 expression levels were lower than levels in Hs1.Tes and Sertoli, respectively. A finding such as this, might explain the presence of ovaric stroma. Also, the study of CNVs for the right gonad showed a heterozygous deletion in 2q14.2 involving the GLI2 gene (glioma-associated oncogene 2 for the zinc finger protein), which encodes a transcription factor that participates in the Hedgehog signaling pathway. The Hedgehog pathway is involved in determining cellular destination and proliferation, and organ pattern during embryo development. ${ }^{(39-41)}$ The differentiation of fetal testis and postnatal and adult ovaries is especially important among such functions. ${ }^{(40,41)}$ Expression of Gli2, together with Gli1 has been observed in fetal Leydig cells. Gli2 and Gli1 might play redundant functions in the differentiation process. ${ }^{(40)}$ Physical and functional interaction of GLI1 and GLI2 has recently been described in humans as regulating the expression of target genes, such as BCL2, MYCN, PTCH2, IL7, and CCD1 in pancreatic tumor cells PANC1. ${ }^{(42)}$ It is still to be determined whether those genes play a similar 
role in the human Sertoli cell-differentiation process. If so, the involvement of one of those genes might impact the right male sexual differentiation.

In case 5, suspected with 46,XX SRY(-) gonadal dysgenesis and assigned sex male, cytogenetic and molecular studies in peripheral blood did not elucidate the clinical condition's origin. It is remarkable that the biopsy of gonadal tissue reports a right ovary and a left ovary with follicular cysts, especially as hormonal studies ruled out hyperandrogenism that might explain the virilization (data not shown). Evidently, there is not a confirmed diagnosis as of this date. Definition of 46,XX SRY (-) gonadal dysgenesis as a primary ovarian failure that leads to premature ovarian insufficiency in otherwise normal 46,XX females. ${ }^{(16)}$ For these reasons, the study presents this as a possible case of gonadal dysgenesis with atypical presentation. Although the underlying cause is unknown in most cases, alterations have been identified in some of the involved genes, including homozigous or compound heterozigous inactivating mutations in the gene of the follicle-stimulating hormone receptor (FSHR), mutations in the BMP15 gene, and mutations in the NR5A1 gene. Inactivating FSHR mutations are inherited in a recessive autosomal pattern; BMP15 mutations are X-linked inherited; and NR5A1 are dominant autosomal, in most cases. ${ }^{(43,44)}$ In another connection, the study of the expression of some genes in gonads of $46, \mathrm{XX}$ SRY(-) patients with a masculine gonadal phenotype suggests that these types of conditions can be explained in some cases by alterations in gene expression. Kojima et al. in 2008, compared SOX9, NROB1, Ad4BP / NR5A1, WT-1, GATA-4 and AMH expression in testis tissue of four $46, \mathrm{XX} S R Y(-)$ patients, with $\mathrm{XY}$ and
XX normal controls. Their study found SOX9 expression levels in testis of these patients to be 1.9 times higher than levels in XY normal testis, while Ad4BP / NR5A1, NROB1 y HAM expression levels were lower compared with the normal XY control. ${ }^{(45)}$ Also, copy number alterations were studied for these genes, although changes were not found at that level. Such findings indicate that $S O X 9$ overexpression is critical in sex determination in 46,XX SRY(-) males, that reduced expression of genes such as Ad4BP/ NR5A1, NROB1, and HAM might also contribute to a masculine phenotype in these patients, ${ }^{(44)}$ and that alterations in expression of genes involved in sexual differentiation are not necessarily related to CNVs. This suggests that it is biologically plausible that epigenetic regulatory mechanisms are related to sex determination and gonadogenesis.

In case 6, with 46,XY $S R Y(+)$ gonadal dysgenesis, SOX9 expression patterns are conspicuous. Results for SRY expression in both gonads were similar to the expression in Sertoli cells, however, SOX9 expression was very low compared to the control. Such low expression levels might explain a failure of the male differentiation process despite the presence of $S R Y$. For the sexual determination of most mammals, Sry gene expression induces the embrionary bipotential gonad to a testis destination via pre-Sertoli cell differentiation. These cells are essential, in fact, for testis differentiation. The expression pattern for Sry is strictly time/space controlled, and it is limited to Sertoli cells precursors. In mice, approximately 4 hours after the start of Sry expression, SOX9 is upregulated in Sertoli cell precursors. Analyses in the bipotential gonad have shown that Sry or Sox9 expression suffices to induce male development. ${ }^{(45,46)}$ For all these reasons, 
the authors highlight the limitation of gene expression assessment with a precise time determination during the embryonic period. The authors consider their paper an approach to gathering knowledge about gene expression and its important role in gonad differentiation in patients with DSD.

Conversely, no direct relationship was found between the SOX3 gene and DSD in the cases of this study. The findings, however, lead to the conclusion that the SOX3 gene expresses in non-differentiated gonadal tissue. In some cases, it might be involved in the clinical phenotype of patients with DSD. This shows that $S O X 3$ overexpression is, as previously discussed, fundamental for intervention in the sexual determination pathway. ${ }^{(30)}$

It is also important to emphasize that malignancy is associated with DSD, mainly with the 46,XY DSD. ${ }^{(47)}$ There's an estimated risk of gonadoblastoma of $15-35 \%$ for gonadal dysgenesis and $3 \%$ for ovotesticular syndrome. In this study, the patient in case 4 with $46, \mathrm{XY}$ SRY(+) ovotesticular syndrome developed a gonadoblastoma, which was detected incidentally during a diagnostic laparoscopy that took a biopsy of the right gonad. Neoplastic transformation has been associated with deregulation of the tandem repetition region of TSPY, an acknowledged tumor-suppressor gene located inside the $\mathrm{Y}$ chromosome gonadoblastoma locus (GBY). ${ }^{(48,49)}$ This gene plays normal roles in masculine germinal cells proliferation and differentiation, but it expresses ectopically in early and late stages of gonadoblastomas, in situ testicular carcinoma (the pre-malignant precusor for all testicular germinal-cell tumors), seminoma and non-seminoma. The aberrant expression of TSPY induces stimulation of protein synthesis, acceleration of cell proliferation, and tumorigenicity. ${ }^{(48)}$
It is worth noting that, currently, fewer than $20 \%$ of patients with DSD receive a precise genetic diagnosis. This justifies a continued exploration of new pathways and genes involved in the process of sex differentiation, ${ }^{(50)}$ as it will allow further understanding of the underlying molecular mechanisms for human sexual development pathology, including, for instance, diagnostic cytogenetic and molecular studies in gonads as a complement to peripheral blood studies. Such studies would be a potential source for understanding the clinical conditions of patients with DSD that are XX or $\mathrm{XY}$ in peripheral blood.

\section{Conclusion}

This study shows that, in some cases, cytogenetic and molecular studies in peripheral blood are insufficient for diagnosing patients with DSD. A complementary approach, including gonadal cytogenetic and molecular analysis, can potentially improve diagnosis and enrich the understanding of DSD clinical manifestations that are XX or XY in peripheral blood.

\section{Availability of data and materials}

The datasets used and/or analyzed during the current study are available from the corresponding author on reasonable request.

\section{Ethics approval and consent to participate}

This research protocol was approved by the Ethics Committee of the Hospital Universitario 


\section{Cytogenetic and molecular characterization in gonadal tissue of patients with ovotesticular... Manotas M, C., et al.}

San Ignacio (FM-CIE-0445-17) and the School of Medicine of the Pontificia Universidad Javeriana.

\section{Patient consent for publication}

The data and results presented in this study were anonymized and we obtained the patients' consent to publish them.

\section{Acknowledgements}

We would like to thank all the patients and families who participated in this study.

\section{Competing interests}

The authors declare that there are no competing interests.

\section{Funding}

This work was funded by HUSI 2017-171. M.G.A., and it also received the Young Researcher grant from COLCIENCIAS (grant 761/2016).

\section{CRediT Taxonomy}

M.C.M., M.G.A., D.G., C.B., M.G., O.M.N., and A.R. designed and performed the experiments and analyzed the data. M.C.M., F.S., C.F., C.C., J.P., and A.R provided technical and conceptual advice and analyzed the results. A.R. and O.M.N supervised the research and analyzed the data. M.C.M., D.G and A.R. wrote the main parts of the manuscript.

\section{References}

1. Snell DM, Turner JMA. Sex Chromosome Effects on Male-Female Differences in Mammals. Curr Biol. 2018;28(22):R1313-24. doi: 10.1016/j.cub.2018.09.018

2. Ngun TC, Ghahramani N, Sánchez FJ, Bocklandt S, Vilain E. The genetics of sex differences in brain and behavior. Front Neuroendocrinol. 2011;32(2):227-46. doi: 10.1016/j.yfrne.2010.10.001

3. Eggers S, Ohnesorg T, Sinclair A. Genetic regulation of mammalian gonad development. Nat Rev Endocrinol. 2014;10(11):673-83. doi: 10.1038/nrendo.2014.163

4. García-Acero M, Moreno O, Suárez F, Rojas A. Disorders of Sexual Development: Current Status and Progress in the Diagnostic Approach. CUR. 2019;13(4):169-78. doi: 10.1159/000499274

5. Li Y, Zheng M, Lau Y-FC. The sexdetermining factors SRY and SOX9 regulate similar target genes and promote testis cord formation during testicular differentiation. Cell Rep. 2014;8(3):723-33. doi: 10.1016/j. celrep.2014.06.055

6. Knower KC, Kelly S, Ludbrook LM, BagheriFam S, Sim H, Bernard P, et al. Failure of SOX9 regulation in 46XY disorders of sex development with SRY, SOX9 and SF1 mutations. PLoS One. 2011;6(3):e17751. doi: 10.1371/journal. pone. 0017751

7. Kanai Y, Koopman P. Structural and functional characterization of the mouse Sox9 promoter: implications for campomelic dysplasia. Hum Mol Genet. 1999;8(4):691-6. doi: 10.1093/ $\mathrm{hmg} / 8.4 .691$

8. Lin L, Achermann JC. Steroidogenic factor-1 (SF-1, Ad4BP, NR5A1) and disorders of testis development. Sex Dev. 2008;2(4-5):200-9. doi: $10.1159 / 000152036$ 
Cytogenetic and molecular characterization in gonadal tissue of patients with ovotesticular... Manotas M, C., et al.

9. Klattig J, Sierig R, Kruspe D, Besenbeck B, Englert C. Wilms' Tumor Protein Wt1 Is an Activator of the Anti-Müllerian Hormone Receptor Gene Amhr2. Mol Cell Biol. 2007;27(12):4355-64. doi: 10.1128/ MCB.01780-06

10. Wilhelm D, Englert C. The Wilms tumor suppressor WT1 regulates early gonad development by activation of Sf1. Genes Dev. 2002;16(14):1839-51. doi: 10.1101/gad.220102

11. Park SY, Meeks JJ, Raverot G, Pfaff LE, Weiss J, Hammer GD, et al. Nuclear receptors Sf1 and Dax1 function cooperatively to mediate somatic cell differentiation during testis development. Development. 2005;132(10):2415-23. doi: 10.1242/dev.01826

12. García-Acero M, Molina M, Moreno O, Ramirez A, Forero C, Céspedes C, et al. Gene dosage of DAX-1, determining in sexual differentiation: duplication of DAX-1 in two sisters with gonadal dysgenesis. Mol Biol Rep. 2019;46(3):2971-8. doi: 10.1007/s11033-019-04758-y

13. Cederroth CR, Pitetti J-L, Papaioannou MD, Nef S. Genetic programs that regulate testicular and ovarian development. Mol Cell Endocrinol. 2007;265-266:3-9. doi: 10.1016/j. mce.2006.12.029

14. Lee PA, Houk CP, Ahmed SF, Hughes IA, International Consensus Conference on Intersex organized by the Lawson Wilkins Pediatric Endocrine Society and the European Society for Paediatric Endocrinology. Consensus statement on management of intersex disorders. International Consensus Conference on Intersex. Pediatrics. 2006;118(2):e488-500. doi: 10.1542/peds.2006-0738

15. Bouty A, Ayers KL, Pask A, Heloury Y, Sinclair AH. The Genetic and Environmental Factors Underlying Hypospadias. Sex Dev. 2015;9(5):239-59. doi: 10.1159/000441988
16. Kohmanaee S, Dalili S, Rad AH. Pure gonadal dysgenesis (46 XX type) with a familial pattern. Adv Biomed Res. 2015; 4:162. doi: 10.4103/2277-9175.162536

17. Özdemir M, Kavak RP, Yalcinkaya I, Guresci K. Ovotesticular Disorder of Sex Development: An Unusual Presentation. J Clin Imaging Sci. 2019; 9:34. doi: 10.25259/JCIS_45_2019

18. Moshiri M, Chapman T, Fechner PY, Dubinsky TJ, Shnorhavorian M, Osman S, et al. Evaluation and management of disorders of sex development: multidisciplinary approach to a complex diagnosis. Radiographics. 2012;32(6):1599-618. doi: 10.1148/ rg.326125507

19. Hersmus R, de Leeuw BHCGM, Stoop H, Bernard P, van Doorn HC, Brüggenwirth HT, et al. A novel SRY missense mutation affecting nuclear import in a $46, \mathrm{XY}$ female patient with bilateral gonadoblastoma. Eur J Hum Genet. 2009;17(12):1642-9. doi: 10.1038/ejhg.2009.96

20. Rocha VBC, Guerra-Júnior G, Marques-deFaria AP, de Mello MP, Maciel-Guerra AT. Complete gonadal dysgenesis in clinical practice: the 46, XY karyotype accounts for more than one third of cases. Fertil Steril. 2011;96(6):1431-4. doi: 10.1016/j.fertnstert.2011.09.009

21. Mohnach L, Fechner PY, Keegan CE. Nonsyndromic Disorders of Testicular Development. In: Adam MP, Ardinger $\mathrm{HH}$, Pagon RA, Wallace SE, Bean LJ, Mirzaa G, et al., editors. GeneReviews ${ }^{\circledR}$. Seattle (WA): University of Washington, Seattle; 1993.

22. Werner R, Merz H, Birnbaum W, Marshall L, Schröder T, Reiz B, et al. 46,XY Gonadal Dysgenesis due to a Homozygous Mutation in Desert Hedgehog (DHH) Identified by Exome Sequencing. J Clin Endocrinol Metab. 2015;100(7):E1022-9. doi: 10.1210/jc.20151314 
Cytogenetic and molecular characterization in gonadal tissue of patients with ovotesticular... Manotas M, C., et al.

23. Granados A, Alaniz VI, Mohnach L, Barseghyan $\mathbf{H}$, Vilain $\mathbf{E}$, Ostrer $\mathbf{H}$, et al. MAP3K1related gonadal dysgenesis: Six new cases and review of the literature. Am J Med Genet C Semin Med Genet. 2017;175(2):253-9. doi: 10.1002/ajmg.c.31559

24. Barbaro M, Balsamo A, Anderlid BM, Myhre AG, Gennari M, Nicoletti A, et al. Characterization of deletions at $9 \mathrm{p}$ affecting the candidate regions for sex reversal and deletion 9p syndrome by MLPA. Eur J Hum Genet. 2009;17(11):1439-47. doi: 10.1038/ejhg.2009.70

25. Délot EC, Vilain EJ. Nonsyndromic 46,XX Testicular Disorders of Sex Development. In: Adam MP, Ardinger $\mathrm{HH}$, Pagon RA, Wallace SE, Bean LJ, Mirzaa G, et al., editors. GeneReviews ${ }^{\circledR}$. Seattle (WA): University of Washington, Seattle; 1993.

26. Moalem S, Babul-Hirji R, Stavropolous DJ, Wherrett D, Bägli DJ, Thomas P, et al. XX male sex reversal with genital abnormalities associated with a de novo SOX3 gene duplication. American Journal of Medical Genetics Part A. 2012;158A (7):1759-64. doi: 10.1002/ajmg.a.35390

27. Haines B, Hughes J, Corbett M, Shaw M, Innes J, Patel L, et al. Interchromosomal insertional translocation at Xq26.3 alters SOX3 expression in an individual with XX male sex reversal. J Clin Endocrinol Metab. 2015;100(5):E815-820. doi: $10.1210 /$ jc.2014-4383

28. Baetens D, Stoop H, Peelman F, Todeschini A-L, Rosseel T, Coppieters F, et al. NR5A1 is a novel disease gene for 46,XX testicular and ovotesticular disorders of sex development. Genet Med. 2017;19(4):367-76. doi: 10.1038/ gim.2016.118

29. Araujo FC, Milsted A, Watanabe IKM, Del Puerto HL, Santos RAS, Lazar J, et al. Similarities and differences of $\mathrm{X}$ and $\mathrm{Y}$ chromosome homologous genes, SRY and SOX3, in regulating the renin-angiotensin system promoters. Physiol Genomics. 2015;47(5):17786. doi: 10.1152/physiolgenomics.00138.2014

30. Sutton E, Hughes J, White S, Sekido R, Tan J, Arboleda V, et al. Identification of SOX3 as an $\mathrm{XX}$ male sex reversal gene in mice and humans. J Clin Invest. 2011;121(1):328-41. doi: 10.1172/ JCI42580

31. Swartz JM, Ciarlo R, Guo MH, Abrha A, Weaver B, Diamond DA, et al. A 46,XX Ovotesticular Disorder of Sex Development Likely Caused by a Steroidogenic Factor-1 (NR5A1) Variant. HRP. 2017;87(3):191-5. doi: 10.1159/000452888

32. Eser M, Ayaz A. Haploinsufficiency of the DMRT Gene Cluster in a Case with 46,XY Ovotesticular Disorder of Sexual Development. Balkan Med J. 2018;35(3):272-4. doi: 10.4274/ balkanmedj.2017.0378

33. García-Acero $\mathbf{M}$, Moreno-Niño $\mathbf{O}$, SuárezObando F, Molina M, Manotas MC, Prieto JC, et al. Disorders of sex development: Genetic characterization of a patient cohort. Molecular Medicine Reports. 2020;21(1):97-106. doi: 10.3892/mmr.2019.10819

34. Moorhead PS, Nowell PC, Mellman WJ, Battips DM, Hungerford DA. Chromosome preparations of leukocytes cultured from human peripheral blood. Exp Cell Res. 1960;20:613-6. doi: 10.1016/0014-4827(60)90138-5

35. Tannour-Louet M, Han S, Corbett ST, Louet J-F, Yatsenko S, Meyers L, et al. Identification of De Novo Copy Number Variants Associated with Human Disorders of Sexual Development. PLOS ONE. 2010;5(10):e15392. doi: 10.1371/ journal.pone.0015392

36. Vidal VP, Chaboissier MC, de Rooij DG, Schedl A. Sox9 induces testis development in $\mathrm{XX}$ transgenic mice. Nat Genet. 2001;28(3):216-7. doi: $10.1038 / 90046$ 
Cytogenetic and molecular characterization in gonadal tissue of patients with ovotesticular... Manotas M, C., et al.

37. Hou J, Shi X, Chen C, Islam MS, Johnson AF, Kanno T, et al. Global impacts of chromosomal imbalance on gene expression in Arabidopsis and other taxa. PNAS. 2018;115(48):E1132130. doi: $10.1073 /$ pnas.1807796115

38. Kamel AK, Abd El-Ghany HM, Mekkawy MK, Makhlouf MM, Mazen IM, El Dessouky N, et al. Sex Chromosome Mosaicism in the Gonads of DSD Patients: A Karyotype/Phenotype Correlation. Sex Dev. 2015;9(5):279-88. doi: 10.1159/000442332

39. McClelland K, Bowles J, Koopman P. Male sex determination: insights into molecular mechanisms. Asian J Androl. 2012;14(1):16471. doi: 10.1038/aja.2011.169

40. Barsoum I, Yao HHC. Redundant and differential roles of transcription factors Gli1 and Gli2 in the development of mouse fetal Leydig cells. Biol Reprod. 2011;84(5):894-9. doi: 10.1095/biolreprod.110.088997

41. Varjosalo M, Taipale J. Hedgehog: functions and mechanisms. Genes Dev. 2008 Sep 15;22(18):2454-72. doi: 10.1101/gad.1693608

42. Giroux-Leprieur E, Costantini A, Ding VW, He B. Hedgehog Signaling in Lung Cancer: From Oncogenesis to Cancer Treatment Resistance. Int J Mol Sci. 2018;19(9):2835. doi: 10.3390/ ijms19092835

43. Breehl L, Caban O. Genetics, Gonadal Dysgenesis. In: StatPearls. Treasure Island (FL): StatPearls Publishing; 2020.

44. Kojima Y, Hayashi Y, Mizuno K, Sasaki S, Fukui Y, Koopman P, et al. Up-regulation of
SOX9 in human sex-determining region on the Y chromosome (SRY)-negative XX males. Clin Endocrinol (Oxf). 2008;68(5):791-9. doi: 10.1111/j.1365-2265.2007.03101.x

45. Eggers S, Sinclair A. Mammalian sex determination-insights from humans and mice. Chromosome Res. 2012;20(1):215-38. doi: 10.1007/s10577-012-9274-3

46. Tanaka SS, Nishinakamura R. Regulation of male sex determination: genital ridge formation and Sry activation in mice. Cell Mol Life Sci. 2014;71(24):4781-802. doi: 10.1007/s00018014-1703-3

47. Délot E, Vilain E. Disorders of Sex Development. In: Reproductive Endocrinology: Physiology, Pathophysiology, and Clinical Management: Elsevier; 2018.

48. Lau Y-FC, Li Y, Kido T. Gonadoblastoma locus and the TSPY gene on the human $\mathrm{Y}$ chromosome. Birth Defects Res C Embryo Today. 2009;87(1):114-22. doi: 10.1002/ bdrc. 20144

49. Kido T, Lau Y-FC. Roles of the Y chromosome genes in human cancers. Asian J Androl. 2015;17(3):373-80. doi: 10.4103/1008$682 X .150842$

50. Wang H, Zhang L, Wang N, Zhu H, Han B, Sun F, et al. Next-generation sequencing reveals genetic landscape in 46, XY disorders of sexual development patients with variable phenotypes. Hum Genet. 2018;137(3):265-77. doi: 10.1007/ s00439-018-1879-y 